\title{
Avaliação de Métodos Alternativos à Citologia no Rastreamento de Lesões Cervicais: Detecção de DNA-HPV e Inspeção Visual
}

\author{
Evaluation of Alternative Methods in Cervical Screening: \\ HPV DNA Detection and Visual Inspection
}

\begin{abstract}
Renata Clementino Gontijo ${ }^{1,2}$, Sophie FM Derchain ${ }^{1}$, Cecília Roteli-Martins ${ }^{1,3}$,
Luis Otávio Zanatta Sarian ${ }^{1}$, Joana Fróes Bragança ${ }^{1}$, Luiz Carlos Zeferino ${ }^{1}$, Samara Messias da Silva ${ }^{1}$
\end{abstract}

\begin{abstract}
RESUMO
Objetivo: avaliar o desempenho da citologia oncológica (CO), de captura híbrida II (CH II) e da inspeção visual com ácido acético na detecção de lesões pré-neoplásicas e neoplásicas cervicais. Métodos: 2281 mulheres foram submetidas a exame clínico além da coleta de material para citologia, para CH II para detecção de DNA-HPV. Foi feita a inspeção visual do colo após aplicação do ácido acético a 5\% (IVA). As mulheres com pelo menos um exame positivo eram convocadas para colposcopia, que também foi realizada em 420 mulheres com todos os exames normais. O desempenho dos testes foi calculado utilizando como padrão ouro a colposcopia com ou sem biopsia.

Resultados: a CO foi anormal em 209 mulheres (9,2\%); a CH II foi positiva em 399 (17,5\%) e em 249 (10,9\%) foram encontradas alterações na IVA. Entre as 2281 mulheres avaliadas, 671 (29,4\%) apresentaram pelo menos um resultado de exame positivo, embora apenas 82 (3,6\%) apresentassem doença confirmada histologicamente (5O NIC1, 20 NIC2, sete NIC3 e cinco carcinomas invasores). As sensibilidades da IVA e da CH II foram semelhantes e significativamente maiores que a da CO. A especificidade da CO foi maior que a da IVA e da CH II. Nos casos com resultado de CO negativo, a IVA apresentou melhor desempenho comparada à CH II.

Conclusão: o desempenho da CO associada à IVA foi melhor que o da CO associada à CH II e do que o da CO isolada.
\end{abstract}

PALAVRAS-CHAVE: Rastreamento para câncer. Colo: lesões pré-neoplásicas. Colo: carcinoma. Citologia.

\section{Introdução}

A maioria dos casos de câncer do colo uterino pode ser evitada por meio do rastreamento. Se a

${ }^{1}$ Departamento de Tocoginecologia da Faculdade de Ciências Médicas e Centro de Atenção Integral à Saúde da Mulher (CAISM) da Universidade Estadual de Campinas (UNICAMP) ${ }^{2}$ Departamento de Ginecologia da Faculdade de Medicina de Jundiaî

${ }^{3}$ Departamento de Ginecologia do Hospital Leonor Mendes de Barros

Correspondência:

Renata C. Gontijo

Rua Olavo Bilac 288/123 - Cambuí

13024-110 - Campinas - SP

e-mail: rgontijo@terra.com.br

Telefone: (19) 3251-4450

Auxilio: Comitê Europeu de Pesquisa da Comunidade Econômica Européia (CEE) - INCO-DEV ICA4-CT-2001- (10013); CNPq processo 300354/01-0 e FAPESP 02/02091-9. qualidade, cobertura e seguimento forem altos, a incidência do câncer cervical pode ser reduzida em até $80 \%{ }^{1,2}$. Entretanto, poucos países em desenvolvimento foram capazes de iniciar e sustentar programas de rastreamento citológico efetivos. Além disto, as campanhas tendem a ser esporádicas e oportunistas, com pouco impacto na incidência do câncer cervical ${ }^{3}$. Esta falha é uma das razões pelas quais este carcinoma permanece em terceiro lugar em freqüência dentre as neoplasias ginecológicas no Brasil ${ }^{4}$.

A citologia oncológica $(\mathrm{CO})$ é o principal método para o diagnóstico precoce das lesões cervicais. Porém, o exame não é método infalível, e resultados de metanálises sugerem sensibilidade variável na detecção de lesões ${ }^{5}$. Desde a colheita do material até a emissão e liberação do resultado, predomina claramente o trabalho ma- 
nual. O desempenho pode, assim, estar relacionado com a qualidade dos recursos humanos envolvidos $^{3,6}$. Por este motivo, métodos alternativos e tecnologicamente mais apropriados do que a $\mathrm{CO}$ têm sido sugeridos para o rastreamento do câncer cervical, entre estes a inspeção visual com ácido acético (IVA) e os testes para detecção pelo papilomavirus humano (HPV) ${ }^{2}$.

A IVA, também chamada de inspeção visual direta, tem recebido atenção considerável como técnica acessivel para países em desenvolvimento ${ }^{7,8}$. A cérvice é lavada com ácido acético a 3 ou a 5\% e observada a olho nu à procura de áreas aceto-brancas. Este método é simples, requer mínima infraestrutura, tem resultado imediato e também pode ser realizado por pessoal paramédico ou enfermeiros, em unidades básicas de saúde ${ }^{1,3,7,8}$. Paralelamente, com o conhecimento do papel do HPV na carcinogênese cervical, verificou-se que o uso dos testes de detecção de DNA-HPV poderia ser de utilidade no diagnóstico precoce de lesões ${ }^{9}$. A captura híbrida (CH II) é procedimento de hibridização molecular, de processamento rápido e leitura confiável para detectar 18 tipos de HPV divididos em grupos de baixo e de alto risco oncogênico ${ }^{9,10}$. Mostra algumas vantagens como sensibilidade maior ou equivalente à $\mathrm{CO}$, necessidade de menor preparo técnico e potencial de autocoleta. Os testes de detecção do HPV associados à citologia podem ser úteis na identificação de mulheres de risco para lesões cervicais mais graves ${ }^{10}$.

Assim, métodos não citológicos podem ser alternativa satisfatória em programas de rastreamento, além de poderem ser utilizados para melhorar o desempenho da CO. A aplicação de um instrumento diagnóstico simples e com boa relação custo-efetividade poderia resultar em melhora da detecção das lesões cervicais, diminuindo, em longo prazo, a incidência e a mortalidade pelo carcinoma do colo uterino. O objetivo deste estudo foi avaliar o desempenho da $\mathrm{CO}, \mathrm{CH}$ II e IVA na detecção de lesões pré-neoplásicas e neoplásicas cervicais.

\section{Pacientes e Métodos}

Estudo descritivo de corte transversal. Foram avaliadas 2281 mulheres atendidas no Centro de Saúde Santa Bárbara, unidade básica de saúde de Campinas, e no Hospital Leonor Mendes de Barros, em São Paulo, que procuraram o serviço para consulta ginecológica de rotina. Entre os meses de fevereiro de 2002 e julho de 2003, foram incluídas mulheres entre 18 e 60 anos de idade, com o colo do útero intacto, sem história de imunossupressão ou de citologia prévia anormal. Após assinarem o termo de consentimento livre e esclarecido, as participantes responderam a um questionário e foram submetidas aos exames. A seqüência obedeceu à seguinte ordem: coleta de material para CO com espátula de Ayre e escova endocervical; coleta de material para detecção do DNA-HPV com esfregaço endocervical e ectocervical e inspeção visual do colo, após aplicação de ácido acético a 5\%.

$\mathrm{O}$ retorno para resultados era marcado em 60 dias e as mulheres que compareceram e que apresentaram pelo menos um exame com resultado positivo foram submetidas à colposcopia, que também foi realizada em 420 mulheres nas quais todos os exames foram normais.

\section{Descrição dos métodos}

O esfregaço citológico foi constituído de duas amostras, representativas do raspado ectocervical e escovado endocervical. A coloração das lâminas foi realizada pelo método de Papanicolaou e foram avaliadas com base no Sistema de Bethesda ${ }^{11}$. Os resultados foram classificados em: alterações inflamatórias, atipias de células escamosas de origem indeterminada (ASCUS), lesões de baixo grau (NIC 1 e HPV), lesões de alto grau (NIC 2 e 3), atipias glandulares de origem indeterminada (AGUS), adenocarcinoma in situ e finalmente carcinoma invasor escamoso ou glandular.

Para análise de DNA-HPV, utilizou-se o teste de CH II (Digene do Brasil Ltda.) obtendo-se material com a utilização de escova endocervical. O processamento foi realizado segundo as instruções do fabricante. Para classificar o resultado da captura de híbridos e quantificar a carga viral, utiliza-se um valor de corte diário, sendo que amostras com emissão de luz maior que o ponto de corte são consideradas positivas e aquelas com emissão de luz menor são consideradas negativas. Uma unidade relativa de luz corresponde a $1 \mathrm{pg} / \mathrm{mL}$ de DNA-HPV, equivalente a 0,1 cópia de vírus/célula. Neste estudo, foram utilizadas somente sondas contendo DNA-HPV de alto risco oncogênico - tipos 16, 18, $31,33,35,39,45,51,52,56,58,59$ e $68^{10}$.

Para realização da IVA, foi aplicado ácido acético a 5\% no colo. Depois de um minuto, o colo foi iluminado com lâmpada elétrica de 100 watts e examinado a olho nu à procura de áreas acetobrancas. A aparência visual foi classificada segundo o Atlas de Inspeção Visual da Cérvice $^{12}$ em: normal, atípico, sugestivo de neoplasia intraepitelial e sugestivo de câncer.

A colposcopia foi realizada com colposcópio DF Vasconcelos e as imagens encontradas foram classificadas, segundo a Nomenclatura Interna- 
cional dos Achados Colposcópicos ${ }^{13}$, em: achados colposcópicos normais, anormais, suspeita de câncer invasor e achados insatisfatórios. Quando a colposcopia apresentava resultado anormal, foram realizadas biópsias, utilizando-se pinças de sacabocado, sendo retiradas amostras das regiões mais alteradas.

Para análise estatística, utilizou-se SAS versão 8.0. Foram calculados a sensibilidade, especificidade e valores preditivos positivo e negativo da $\mathrm{CO}, \mathrm{CH}$ II e IVA, com intervalo de confiança (IC) 95\%. Para esta avaliação, foram incluídas exclusivamente as mulheres submetidas à colposcopia. Tomou-se como padrão-ouro a colposcopia, com ou sem biópsia. As mulheres cujo diagnóstico histológico final foi compatível com NIC 1 ou mais foram consideradas como diagnóstico final positivo. Quando a colposcopia foi normal ou quando a biópsia apresentou cervicite ou metaplasia, foram consideradas como diagnóstico final negativo. Finalmente foi avaliada a distribuição das mulheres segundo o resultado de todos os testes, iniciando pela $\mathrm{CO}$, seguido da $\mathrm{CH}$ II e da IVA e o diagnóstico final. Este estudo foi aprovado pelo Comitê de Ética em Pesquisa da Faculdade de Ciências Médicas da UNICAMP e do Hospital Leonor Mendes de Barros e também pela Comissão Nacional de Ética em Pesquisa (CONEP).

\section{Resultados}

A citologia apresentou resultado em 90,8\% das mulheres. Atipias celulares foram encontradas em 209 (9,2\%) resultados, sendo 147 (6,5\%) ASCUS, $10(0,5 \%)$ AGUS, 35 (1,5\%) lesões escamosas de baixo grau (HPV/NIC 1) e $16(0,7 \%)$ lesões escamosas de alto grau (NIC 2 ou NIC 3). Somente um resultado foi sugestivo de câncer invasor. Observamos também que em aproximadamente $18 \%$ das mulheres foi detectado o DNA-HPV. Em relação à IVA, 10,9\% das mulheres apresentaram o resultado positivo (Tabela 1 ).

Na Tabela 2, comparando os resultados da $\mathrm{CO}$, da $\mathrm{CH}$ II e da IVA, observamos que entre as mulheres com resultado de $\mathrm{CO}$ negativo, a grande maioria apresentou também o colo normal à inspeção visual, embora em 251 tenha sido detectado o DNA viral. Entretanto, 163 mulheres com resultados de $\mathrm{CO}$ e $\mathrm{CH}$ II negativos apresentaram alguma alteração na inspeção visual do colo. Dentre as mulheres com resultado de $\mathrm{CO}$ positivo, a grande maioria apresentou o colo normal à IVA, embora tenha sido detectado o DNA-HPV em quase metade destas mulheres. Apenas 22 mulheres apresentaram os três exames positivos, e, por outro lado, 1610 mulheres apresentaram todos os três exames negativos.

Tabela 1 - Distribuição das mulheres segundo o resultado dos exames.

\begin{tabular}{|c|c|c|}
\hline Exame & $\mathbf{n}$ & $\%$ \\
\hline \multicolumn{3}{|l|}{ Citologia oncológica } \\
\hline Normal & 2072 & 90,8 \\
\hline ASCUS $^{1}$ & 147 & 6,4 \\
\hline AGUS² & 10 & 0,4 \\
\hline Lesão escamosa de baixo grau & 35 & 1,53 \\
\hline Lesão escamosa de alto grau & 16 & 0,7 \\
\hline Carcinoma & 1 & 0,04 \\
\hline \multicolumn{3}{|l|}{ Captura de híbridos II } \\
\hline Negativa $<1 \mathrm{RLU}^{3}$ & 1882 & 82,5 \\
\hline Positiva $\geq 1 \mathrm{RLU}$ & 399 & 17,4 \\
\hline \multicolumn{3}{|l|}{ IVA $^{4}$} \\
\hline Negativa & 2032 & 89,0 \\
\hline Positiva & 249 & 10,9 \\
\hline
\end{tabular}

ASCUS: células escamosas atípicas de significado indeterminado; AGUS: células glandulares atípicas de significado indeterminado; RLU: unidade relativa de luz; IVA: inspeção visual com ácido acético.

Tabela 2 - Comparação entre resultados positivos e negativos da citologia oncológica captura de híbridos II (CH II) e inspeção visual com ácido acético a 5\% nas 2281 mulheres avaliadas.

IVA

\begin{tabular}{llrr} 
& & Negativa & Positiva \\
\hline Citologia negativa & CH II negativa (<1 RLU) & 1610 & 163 \\
& CH II positiva (>1 RLU) & 251 & 48 \\
Citologia positiva & CH II negativa (<1 RLU) & 93 & 16 \\
& CH II positiva (>1 RLU) & 78 & 22 \\
Total & & 2032 & 249 \\
\hline
\end{tabular}

IVA: inspeção visual com ácido acético; RLV: unidade relativa de luz.

Observamos que, das 671 mulheres $(29,4 \%)$ com pelo menos um exame alterado e que foram referidas para colposcopia, 172 não compareceram, sendo consideradas então exame positivo não verificado. Entre as 499 mulheres com pelo menos um exame alterado e que foram avaliadas com colposcopia, 297 não apresentaram imagem suspeita e não foram submetidas a biópsia. Finalmente, entre 420 mulheres submetidas à colposcopia na primeira consulta, randomizadas, 18 apresentavam imagems anormais e foram submetidas a biopsia. Entre as mulheres que foram biopsiadas, os resultados histológicos foram cervicite em 138, HPV/NIC 1 em 50, NIC 2 em 20, NIC 3 em sete e carcinoma invasor em cinco (Tabela 3 ). 
Tabela 3 - Distribuição das mulheres segundo o diagnóstico final.

\begin{tabular}{lrrr}
\hline Diagnóstico & $\mathbf{n}$ & $\%$ & \% Biopsia \\
\hline Sem colposcopia, todos os exames negativos & 1190 & 52,2 & 7,3 \\
Sem colposcopia com pelo menos um exame positivo & 167 & 17,6 & 13,2 \\
Com colposcopia, todos os exames negativos, sem biopsia & 402 & 0,8 & 62,7 \\
Com colposcopia por exame positivo, sem biópsia & 302 & 8,9 & 22,7 \\
Com colposcopia, todos os exames negativos, com biopsia & 18 & & 9,1 \\
Com colposcopia por exame positivo, com biópsia & 202 & & 3,2 \\
Cervicite/metaplasia & 138 & & 2,3 \\
HPV/NIC 1 & 50 & & 100,0 \\
NIC 2 & 20 & 100,0 & \\
NIC 3 & 7 & 5 & \\
Câncer invasor & 2281 & & \\
Total & & & \\
\hline
\end{tabular}

Na Tabela 4 observamos que a CH II $(65,8 \%)$ e a IVA $(59,7 \%)$ apresentaram sensibilidade semelhante e significativamente maior do que a $\mathrm{CO}$ $(51,2 \%)$. A especificidade da CO $(84,9 \%)$ foi significativamente maior que a da IVA $(78,1 \%)$ e da $\mathrm{CH}$ II $(74,5 \%)$. Os valores preditivos negativos da $\mathrm{CO}$, CH II e IVA foram, respectivamente, 94,7, 95,7 e $95,2 \%$; os valores preditivos positivos foram $25,20,2$ e $21,1 \%$, respectivamente.

Na Tabela 5, observa-se que, quando avaliamos o resultado dos três exames realizados em seqüência, observamos que, entre as 22 mulhe- res com resultado positivo nos três exames, 11 apresentaram doença histológica. A proporção de doença foi menor nas mulheres que apresentaram alterações na $\mathrm{CO}$ e o colo normal à inspeção visual ou $\mathrm{CH}$ II positiva. É importante observar nesta tabela que a citologia não detectou $48 \%$ das mulheres com lesão histológica, isto é, num total de 82 mulheres com diagnóstico histológico positivo, 40 apresentaram resultado de $\mathrm{CO}$ negativo. Nestes 40 casos, a $\mathrm{CH}$ II contribuiu na detecção de 18 casos e a IVA contribuiu na detecção de 36 casos.

Tabela 4 - Desempenho da citologia oncológica (CO), da captura de híbridos II (CH II) e inspeção visual com ácido acético (IVA) a $5 \%$.

\begin{tabular}{lcccccc}
\hline Estimativa bruta & \multicolumn{2}{c}{ CO } & \multicolumn{2}{c}{ CH II } & \multicolumn{2}{c}{ IVA } \\
& $\%$ & IC (95\%) & $\%$ & IC (95\%) & $\%$ & IC (95\%) \\
\hline Sensibilidade & 51,2 & $48-54,4$ & 65,8 & $62,8-68,9$ & 59,7 & $56,6-62,9$ \\
Especificidade & 84,9 & $82,6-87,2$ & 74,5 & $71,7-77,4$ & 78,1 & $75,5-80,8$ \\
VPP & 25 & - & 20,2 & - & 21,1 & - \\
VPN & 94,7 & - & 95,7 & - & 95,2 & - \\
\hline
\end{tabular}

\section{Discussão}

O câncer de colo do útero é problema de saúde pública em muitas regiões do mundo, apesar de a tecnologia para seu diagnóstico precoce estar disponível há muitas décadas. A proposta de um programa de rastreamento é de, além de diagnosticar o câncer em estádios iniciais, detectar e remover lesões de alto grau, prevenindo sua potencial progressão para carcinoma ${ }^{14}$. Geralmente, estes programas são baseados em citologia e sua desvantagem é que requerem laboratórios estabelecidos e citologistas e citotécnicos bem trei- nados $^{3}$. Por este motivo, métodos opcionais para rastreamento têm sido descritos atualmente. Existe substancial interesse no uso dos testes de biologia molecular como ferramenta de rastreamento, baseado na premissa de que a detecção do HPV poderia apresentar bom desempenho diagnóstico, sendo melhor reproduzivel e mais adaptado para a prática clínica que a citologia convencional ${ }^{14}$. Os testes para detecção de DNA-HPV podem ser processados em unidades laboratoriais de referência, sem a necessidade de pessoal com treinamento intensivo. Já a leitura dos esfregaços da CO depende de citologistas e patologistas com adequada capacitação. 
Tabela 5 - Distribuição das mulheres segundo os exames realizados em seqüência (CO, CH II, IVA) e a presença de doença.

\begin{tabular}{|c|c|c|c|c|c|c|c|c|}
\hline \multirow[t]{2}{*}{ CO } & \multirow[t]{2}{*}{$\mathrm{CH}$ II } & \multirow[t]{2}{*}{ IVA } & \multirow{2}{*}{$\begin{array}{c}\text { Total de mulheres } \\
n\end{array}$} & \multirow{2}{*}{$\begin{array}{c}\text { Não verificado* } \\
n\end{array}$} & \multicolumn{2}{|c|}{ Sem doença** } & \multicolumn{2}{|c|}{ Com doença ${ }^{\star \star \star}$} \\
\hline & & & & & $\mathrm{n}$ & $\%$ & $\mathrm{n}$ & $\%$ \\
\hline+ & + & + & 22 & 0 & 11 & 50 & 11 & 50 \\
\hline+ & + & - & 78 & 15 & 38 & 60 & 25 & 40 \\
\hline+ & - & + & 16 & 0 & 14 & 87 & 2 & 13 \\
\hline+ & - & - & 93 & 26 & 63 & 94 & 4 & 6 \\
\hline- & + & + & 48 & 3 & 29 & 64 & 16 & 26 \\
\hline- & - & + & 163 & 14 & 129 & 87 & 20 & 13 \\
\hline- & + & - & 251 & 114 & 135 & 98 & 2 & 2 \\
\hline- & - & - & 1610 & 1190 & 418 & 99 & 2 & $<1$ \\
\hline Total & & & 2281 & 1362 & 837 & & 82 & \\
\hline
\end{tabular}

*Mulheres não submetidas à colposcopia (faltosas). ${ }^{* *}$ Mulheres com colposcopia normal ou biópsia normal/cervicite. ${ }^{* *}$ Mulheres com biópsia compatível com NIC 1 ou mais grave. CO: citologia oncológica; $\mathrm{CH}$ II: captura de híbridos II; IVA: inspeção visual com ácido acético.

Por outro lado, o papel da detecção do DNAHPV no rastreamento é controverso. Nosso estudo mostrou taxa de positividade da CH II de 17,5\%. Como quase metade da população estudada tem menos que 35 anos, as infecções subclínicas pelo HPV são comuns. Deve se considerar que a grande maioria das mulheres infectadas apresenta infecção transitória que, em curto período de tempo, entra em equilíbrio com o seu sistema imunológico sem resultar em doença. Em apenas algumas, a infecção é associada com lesão clínica e resulta no desenvolvimento de neoplasia intraepitelial $^{2,14}$. Em estudo realizado com 2098 mulheres usando o teste de detecção de HPV como método de rastreamento, Ratnam et al. ${ }^{15}$ encontraram $10,8 \%$ de resultados positivos. Já no estudo realizado por Denny et al. ${ }^{16}$ a taxa de positividade foi de $16,2 \%$. Testes de triagem devem apresentar alto valor preditivo positivo. Alta taxa de resultados falso-positivos leva à repetição de exames, com conseqüente aumento do custo, ansiedade da mulher e perda de tempo ${ }^{17}$.

A IVA tem recebido atenção atualmente como técnica para redução das taxas de carcinoma cervical em lugares onde programas de rastreamento baseados em citologia não são adequa$\operatorname{dos}^{8}$. Neste estudo, a IVA apresentou resultado positivo em $10,9 \%$ das mulheres, ao passo que a citologia foi alterada em 9,2\%, mostrando resultados semelhantes aos da literatura. Sankaranarayanan et al. ${ }^{18}$ avaliaram $3000 \mathrm{mu}-$ lheres e encontraram 298 IVA alteradas $(9,9 \%)$ e 307 com citologias positivas (10,2\%). Belinson et al. ${ }^{7}$, avaliando 1997 mulheres, encontraram positividade da IVA em $28 \%$. Em relação ao desempenho dos exames, nossa casuística mostrou que a CH II e a IVA apresentaram sensibilidade significativamente maior do que a CO. Já a especifici- dade da $\mathrm{CO}$ foi significativamente maior que a da IVA e da CH II. Estes resultados podem ser explicados pela qualidade da cobertura citológica da nossa região, mostrando melhor desempenho da $\mathrm{CO}$ na detecção de casos positivos. Estudos conduzidos na China, África e Índia também mostraram desempenho da IVA melhor ou igual ao da citologia na correta identificação de doenças, porém com especificidade menor que a citologia ${ }^{7,8,18}$.

Para algumas regiões, os programas de rastreamento baseados nas alterações visuais do colo têm vantagens significativas sobre aqueles baseados em citologia e/ou nos testes para detecção de HPV: são baratos, os materiais usados são de fácil reposição, o exame é de simples realização e, por apresentarem resultado imediato, minimizam as perdas de seguimento e eventualmente permitem avaliação e tratamento em uma só consulta ${ }^{3,18}$. Um estudo na África do Sul comparou mulheres submetidas à crioterapia imediatamente após o resultado de IVA positivo com mulheres não rastreadas e verificou uma redução na incidência do câncer cervical de 26 a $32 \%$. Os autores consideraram que os efeitos adversos da crioterapia foram minimos comparados com o risco daquelas mulheres de desenvolverem câncer ${ }^{19}$. Porém esta, estratégia pode ter importantes implicações, visto que o teste apresenta especificidade relativamente baixa e número substancial de mulheres sem evidência histopatológica de doença serão submetidas a tratamento desnecessário.

Sankaranarayanan et al. ${ }^{18}$ também advogam o tratamento realizado com cauterização ou crioterapia na primeira visita, logo após o resultado da IVA. Referem que os custos diminuem com o tratamento em uma única consulta e que o tratamento das mulheres sem doença devido a resultado falso-positivo pode ser considerado como 
"um preço aceitável a pagar pelo efetivo controle do carcinoma cervical". Considerando, na nossa casuística, o valor preditivo positivo da IVA de apenas $21,1 \%$, o tratamento imediato nesta população teria levado a número excessivo de cauterizações em mulheres sadias. Neste estudo, após a coleta dos exames, a mulher teve seu retorno agendado para resultado. Quando um exame mostrou resultado positivo, ela foi encaminhada e submetida a colposcopia. Observamos que 172 das 671 mulheres com pelo menos um exame alterado não voltaram para a colposcopia, o que poderia justificar o tratamento imediato mesmo que excessivo. Por outro lado, cinco mulheres apresentaram câncer invasor, e neste caso, a cauterização no momento da primeira consulta sem avaliação histopatológica teria sido incorreta. Assim, é importante salientar que o tratamento imediato pode ser visto como uma opção ética e racional aceitável somente nas situações em que a infra-estrutura é pobre e os recursos são limitados ${ }^{19}$.

A CH II e a IVA foram utilizadas como métodos associados à $\mathrm{CO}$ e não como seus substitutos. Em mulheres com resultado de CO negativa o acréscimo da IVA diagnosticou 36 casos com doen-ça, ao passo que a $\mathrm{CH}$ II contribuiu na detecção de 18 casos. A contribuição da $\mathrm{CH}$ II para o diagnóstico de lesões cervicais não foi substancial. Já a IVA associada à $\mathrm{CO}$ foi de grande utilidade no rastreamento de lesões, mostrando melhor desempenho que a $\mathrm{CO}$ isolada na detecção de doença histológica.

A IVA pode ser de grande valia em serviços que disponham de colposcópio e ginecologista capacitado que possa complementá-la em casos suspeitos. Para que possa ser realizada de forma rotineira, seria necessário apenas o treinamento do pessoal responsável pela coleta da $\mathrm{CO}$. Este treinamento ofereceria beneficio substancial na detecção das lesões cervicais, sem aumento excessivo dos custos para os programas de controle de câncer cérvico-uterino.

\section{ABSTRACT}

Objective: to evaluate the performance of Pap smear, hybrid capture II (HC II), and visual inspection with acetic acid in the detection of pre-invasive and invasive cervical lesions. Methods: a total of 2281 women were submitted to a clinical exam, including Pap smear, HC II for HPV DNA detection and visual inspection with $5 \%$ acetic acid (VIA). When at least one of the tests was positive, colposcopy was performed and targeted biopsies were taken from suspicious lesions. Colposcopy was also performed in 420 women with negative results. Test performance was evaluated, using colposcopy as the gold standard, with or without biopsy.
Results: Pap smear, VIA and HC II were positive in 9.2, 10.9 and $17.5 \%$ of all women screened, respectively. Although at least one positive test was found in 671 women (29.4\%), only $82(3.6 \%)$ presented histologically confirmed disease (50 NIC1, 20 NIC2, 7 NIC3, and 5 invasive carcinoma). VIA and HC II sensitivities were similar and significantly higher than Pap smear. Pap smear showed better specificity than VIA and than HC II. In women with a negative Pap smear result, VIA showed better performance than HC II.

Conclusion: Pap smear combined with VIA performed better than Pap smear combined with HC II or than Pap smear alone.

KEYWORDS: Cancer screening. Cervix: pre-neoplastic lesions. Cervix: carcinoma. Cytology.

\section{Agradecimentos}

Agradecemos a Eline Borim Montemor pela leitura das lâminas de citologia, a Elisabete Campos, Denise Pita e Lúcia Carvalho pela realização dos exames de captura de híbridos, ao Professor Attila Lorincz pela doação dos kits de CH II e à Secretaria de Saúde da Prefeitura Municipal de Campinas.

\section{Referências}

1. Mandelblatt JS, Lawrence WF, Womack SM, et al. Benefits and costs of using HPV testing to screen for cervical cancer. JAMA 2002; 287:2372-81.

2. Syrjänen KJ, Syrjänen SM. Papillomavirus infections in human pathology. $1^{\text {st }}$ ed. Chichester: John Wiley \& Sons; 2000.

3. Sankaranarayanan R, Budukh AM, Rajkumar R. Effective screening programs for cervical cancer in low- and middle-income developing countries. Bull World Health Organ 2001; 79:954-62.

4. Ministério da Saúde. Secretária de Assistência à Saúde. Instituto Nacional de Câncer - INCA. Estimativas da incidência e mortalidade por câncer. Rio de Janeiro: INCA; 2002.

5. Bastian L, Datta S, Hasselblad V, Hickey J, Myers E, Nanda K. Evidence report: evaluation of cervical cytology. Rockville: AHCPR; 1999. (AHCPR Publication, 99-E010).

6. Cortese C; American Society of Cytopathology. Cervical Cytology Practice Guidelines. Acta Cytol 2001; 45:201-26.

7. Belinson JL, Pretorius RG, Zhang WH, Wu LY, Qiao YL, Elson P. Cervical cancer screening study by simple visual inspection after acetic acid. Obstet Gynecol 2001; 98:441-4. 
8. Visual inspection with acetic acid for cervical cancer screening: test qualities in a primary-care setting. University of Zimbabwe/JHPIEGO Cervical Cancer Project. Lancet 1999; 353:869-73.

9. Clavel C, Masure M, Bory JP, et al. Human papillomavirus testing in primary screening for detection of high-grade cervical lesions: a study of 7932 women. Br J Cancer 2001; 89:1616-23.

10.Lörincz AT, Castle PE, Sherman ME, et al. Viral load of human papillomavirus and risk of CIN 3 or cervical cancer. Lancet 2002; 360:228-9.

11.Kurman RJ, Solomon D. The Bethesda System for reporting cervical/vaginal cytologic diagnoses. $1^{\text {st }} \mathrm{ed}$. New York: Springer-Verlag; 1994.

12.Blumenthal P. Atlas for unaided visual inspection of the cervix. $1^{\text {st }}$ ed. Baltimore: JHPIEGO; 1997.

13.Stafl A, Wilbanks GD. An international terminology of colposcopy: report of the Nomenclature Committee of the International Federation of Cervical Pathology and Colposcopy. Obstet Gynecol 1991; 77:313-4.

14. Saslow D, Runowicz CD, Solomon D, et al. American Cancer Society Guideline for the early detection of cervical neoplasia and cancer. CA Cancer J Clin 2002; 52:342-62.
15. Ratnam S, Franco EL, Ferenczy A. Human papillomavirus testing for primary screening of cervical cancer precursors. Cancer Epidemiol Biomarkers Prev 2000; 9:945-51.

16.Denny L, Kuhn L, Pollack A, Wainwright H, Wright TC Jr. Evaluation of alternative methods of cervical cancer screening for resource-poor settings. Cancer 2000; 89:826-33.

17.Nanda K, Myers ER. Selecting a cervical cytology screening test- what are the issues? J Clin Outcomes Manag 2001; 8:29-32.

18.Sankaranarayanan R, Wesley R, Somanathan T, et al. Visual inspection of the uterine cervix after the application of acetic acid in the detection of cervical carcinoma and its precursors. Cancer 1998 , 83:2150-6.

19.Goldie SJ, Kuhn L, Denny L, Pollack A, Wright TC. Policy analysis of cervical cancer screening strategies in low-resource settings: clinical benefits and cost-effectiveness. JAMA 2001; 285:3107-15.
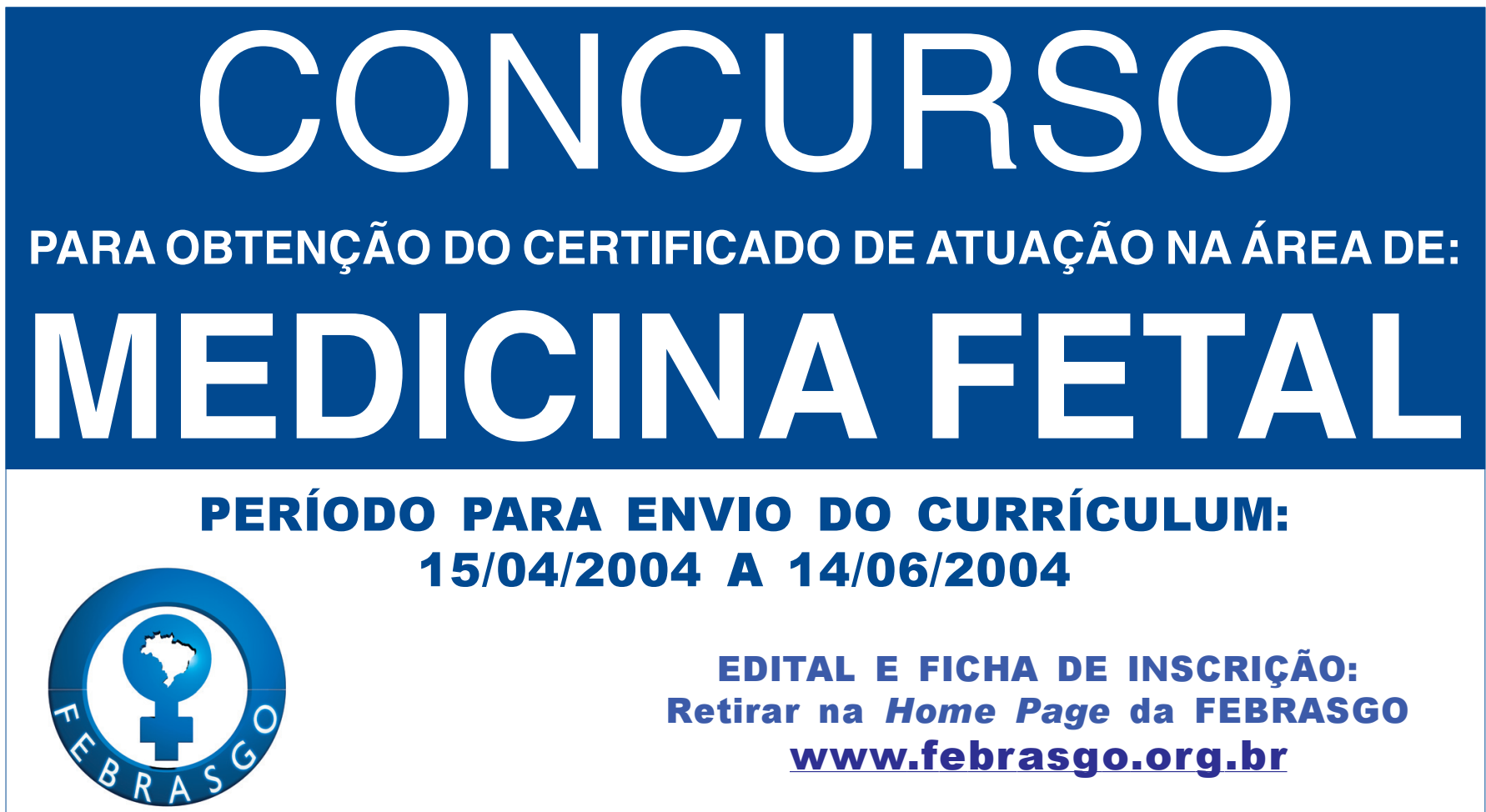

\author{
EDITAL E FICHA DE INSCRIÇÃO: \\ Retirar na Home Page da FEBRASGo \\ www.febrasgo.org.br
}

ENVIAR PARA SECRETARIA EXECUTIVA DA FEBRASGO:

Av. das Américas, 8445 - sala 711

Barra da Tijuca - Rio de Janeiro - RJ

22793-081

Tel.: (0xx21) 2487-6336 